\title{
Biotechnology, Mass Cell Culture
}

National Cancer Institute

\section{Source}

National Cancer Institute. Biotechnology, Mass Cell Culture. NCI Thesaurus. Code

C18657.

Techniques using equipment such as a hollow fiber apparatus or roller bottles for high volume maintenance or growth of animal, plant, or insect cells in vitro. 